\title{
Human Rights and Public Health in the International HIV Response: Issues of Contested Control, Treatment and Prevention: Human Rights and Public Health, Different...But the Same?
}

\author{
Edward Reis ${ }^{1,2}$ \\ 1. Australasian Society of HIV Medicine Inc. Locked Bag 5057, Darlinghurst, NSW 1300, Australia \\ 2. School of Public Health and Community Medicine, University of NSW, UNSW Medicine NSW 2052 Australia
}

Received: March 8, 2015 / Accepted: March 31, 2015 / Published: March 31, 2015.

\begin{abstract}
From its earliest formulation, the international HIV response has attempted to harness human rights as a central element of public health practice. Policy initiatives aimed at eliminating stigma and discrimination of affected people would enable them to access health and social services, practice safe behaviors and thereby protect public health. However, this response was characterized by tensions between differing perceptions of public health and human rights and, with the advent of effective treatments, between those who regarded behavioral and biomedical interventions as competing, if not mutually exclusive, approaches. A central theme in all of these elements has been control: control of the virus, control of the behaviors of people affected, control of policy and control of rights. HIV infection is both a cause and a consequence of human rights abuses, but for many people these two aspects are compounded into the same lived predicament; a predicament over which many feel they should have control. The test-and-treat debates at the 2010 IAS Conference demonstrated this as presenters and participants openly clashed over proposals to implement what many see as coercive measures in settings where viral transmission and the public health/human rights collaboration might both be regarded as now "out of control". This paper will explore issues of control in the international HIV response and how authority, in the forms of law and justice, is contested in that response.
\end{abstract}

Key words: Treatment-as-prevention, treatment and prevention, human rights, international HIV policy.

\section{Introduction}

The politics of treatment has always been a feature of HIV programs, even before the advent of HIV treatments. Nowadays, treatment as prevention is radically challenging earlier understandings of the right to health and what that means for the individual. The present paper reviews the discussion of treatment as prevention at the 2012 international AIDS conference in Washington, and the ways that this was structured to shape policy and programmatic responses during the years since that event. The paper

Corresponding author: Edward Reis, research fields: human rights, public health and international HIV policy. E-mail: edward.reis@ashm.org.au. also considers what the implications of this might have been for supporting treatment and prevention in HIV programs in Australia's regional HIV partnerships. From a more theoretical perspective, the paper will consider the positioning of human rights within this approach and the ways that people with and affected by HIV are subjected by a treatment as prevention anthem.

The title to this paper may well suggest a sense of confusion about some rather fundamental concepts and approaches in the field of HIV, and if we are to look at the programing of recent International AIDS Conferences, that confusion is evident at a higher level of policy development. 

Treatment and Prevention: Human Rights and Public Health, Different...But the Same?

\section{Discussion}

In a paper four years ago, Barry Adam presented a telling analysis of the ways that prevention has been contextualised in the plenary sessions of international AIDS conferences between 2002 and 2010 [1]. Adam showed that of the 21 plenary speakers addressing prevention at those conferences, 13 regarded it "primarily or exclusively as a biomedical technology." [1] In the same paper, he noted that across the same span of conference plenaries and with regard to the populations supposedly targeted for prevention, only three presenters addressed injecting drug users, two addressed women and just one addressed MSM [1]. That's over ten years. And most of the speakers addressing these populations were physicians or public health authorities.

With respect to Adam, who also presented at the 2014 AIDS Conference in Melbourne, Australia, the author took the same lens, as did Adam, to the 2012 AIDS Conference plenaries held in Washington D.C.. Of the 17 plenary presenters, 10 were variously clinicians, ID physicians, microbiologists and immunologists public health and UN authority representatives, 5 were community representatives or leaders (one of whom, Debbie, was a transgender, ex drug user and sex worker - a boon no doubt to programmers-after all, she covered off 3 bases of affected populations in just 1 speaker).

The author altered the lens somewhat to see that of 17 plenary speakers, at least 11 held positions either in the UN family stable or related research institutes. With respect to key affected populations, 2 spoke on women, 1 on children and youth, 1 on sex workers, 1 on transgender people and 1 on MSM.

Of those 17 plenary speakers, 12 addressed prevention. Consistent with Adam's observations between 2002 and 2010, the 2012 plenary titles indicated the positioning of prevention within current HIV discourse and policy. Titles such as, "Ending the HIV Epidemic: From Scientific Advances to Public Health Implementation" (23/07/12), "Viral
Eradication-The Cure Agenda" (24/07/12),

"Implementation Science: Making the New Prevention Revolution Real" (24/07/12), "Expanding HIV Testing and the Use of ARVs for Treatment and Prevention (26/07/12)", and "Science and Implementation to Turn the Tide on TB" (27/07/12) [2].

The key theme in all of these presentations was implementation and indeed this was one of the overriding 2012 conference messages. We have the science, the issue now is implementation. There was much talk of curing AIDS and achieving an "AIDS free generation". Noble and highly desirable goals.

Two years previously in Vienna, where the 2010 AIDS Conference theme was "Rights Here Right Now" [3], the challenge to the science of treatment as prevention was twofold-firstly that it was largely based on mathematical modelling and confined to very particular conditions which could and would not be replicated in the real world [4] and that while such experimental conditions might indicate efficacy, this should not be confused with any potential effectiveness [5]. Secondly, treatment as prevention was strongly critiqued from a human rights perspective. Not surprising, perhaps, given that the theme of that conference was human rights. At Vienna the author was disturbed by the ways that test and treat strategies privileged public health interventions over the rights of people affected by HIV; at the same time the author was intrigued by the response of treatment as prevention advocates, which was to promote delivery of this agenda in something called a "human rights framework". Surprisingly, the author observed at the Washington 2012 conference that this human rights framework was largely no longer mentioned or referred to; had it been dismantled?

Had it served its purpose as a scaffolding for something much stronger-something now being termed "the science of implementation"? Or was a human rights framework just too cumbersome after all, when something more streamlined and efficient is needed to implement science? 

Treatment and Prevention: Human Rights and Public Health, Different...But the Same?

Whatever the reason, human rights appeared to have become something of a token albeit obligatory line in the context of curing or freeing a generation of AIDS. What references there were to human rights were generally confined to calls for respect of rights by reducing stigma and discrimination. In Washington, the author wondered if we had "done" human rights in Vienna, and were now onto something more important.

The Words of Welcome from the Conference Co-Chairs noted that:

...we now have a tremendous new toolkit to fight HIV ...the pay —offs ...from the efforts of determined researchers and courageous trial participants...our dreams of an HIV cure and vaccine appear more attainable... Our fervent hopes... must be tempered by the realities of today-financial restraints, scientific mysteries, resistance to evidence-based HIV prevention strategies... and the ...challenges of bringing effective interventions to scale [6].

The leading plenary speaker asserted that "Science has provided highly effective interventions to prevent and treat HIV-1 infection. Now we have the moral responsibility to scale-up implementation globally to ensure the end of the HIV/AIDS pandemic" [7].

What exactly did that moral responsibility amount to? Plenary speaker after plenary speaker gave us the answer, as they told us that our obligation was to take up these tools to end AIDS, use them, apply the new science, and use funds appropriately to get more people onto treatment as prevention programs. The challenges that they articulated were all about implementation of the science. This was our new moral responsibility. Not it seems, to interrogate treatment as prevention, for this stance was to risk being construed as "resistance to... evidence - based HIV prevention strategies" [6], nor was it to suggest that presumed public health benefit is something different from, and at times at odds with, the human rights of people subjected by these strategies. Implementing treatment as prevention, research toward a cure and using funding efficiently were identified as the challenges to be overcome.
So a major trope of the conference was set; science had not only given us treatments, it had now given us prevention as well. Job done.

Now the task remaining, the responsibility, the moral obligation, was for us to implement that science. Job remaining.

Many conference sessions described how we might go about overcoming those challenges to implementing the science. But their focus was curiously devoid of discussions about what we understand as social practices, social movements and social transformations. Furthermore, notions of agency, consent and choice were missing in a discourse that clearly presumed the subject, for this liberating science of treatment- asprevention, was a universal template, obliged to policy compliance in the dual name of everyone's public health and their own human rights.

Many conference sessions talked about 'social protection schemes' designed to reduce poverty and vulnerability; insurance, protective legislation, CCT-conditional cash transfer incentives for HIV testing and treatment adherence. UNAIDS, UNICEF and ILO were taking up these schemes and in 2011 UNAIDS released the HIV and Social Protection Guidance Note [8]. The studies presented in these conference sessions demonstrated measures of benefits, including, it was claimed, production of "an empowered citizen." The author does not doubt that economic opportunities are needed by many people affected by HIV, but the author does not think that marginalisation and vulnerability are solely the result of economic deprivation. Economists presented on ways that social protection schemes would provide opportunities to ensure greater treatment coverage of HIV affected populations.

Many of these presenters referenced the "Investment Framework", the 2011 UNAIDS Issues Brief, A New Investment Framework for the Global HIV Response. This Framework is "intended to facilitate more focused and strategic use of scarce resources" [9]. Since its release, this framework had become a key planning 

Treatment and Prevention: Human Rights and Public Health, Different...But the Same?

tool and reference point for many donors assessing their HIV aid programs. For many of these presenters however, social protection was equated solely with economic interventions. The presumption being that improved economic status equated to a more compliant subject, portrayed as an empowered citizen, and that citizens requiring HIV treatment for life will be in need of such social protection schemes.

Other sessions cast sustainability, that much abused term, increasingly as a matter of economics; where will the money come from?

The author does not wish to suggest that economics is not a crucial factor across the spectrum of HIV agendas. What struck me in Washington was the narrow focus of perceived challenges and a presumed resistance to science; challenges that were presented overwhelmingly as economic, structural and programmatic. Where were the people? The author wondered where were the complex multilayered lives of people who engage in a host of social practices across a variety of social settings and who make choices and decisions according to their own logics, who understand their human rights and vulnerabilities from their experiences and needs? At least we had heard these voices in Vienna; voices objecting and challenging from the floor, voices stating that their human rights were not the same thing as the public health goals of scientists and HIV bureaucrats promoting treatment as prevention, being heard from the stage.

Of course many of those voices were not present in Washington; US entry restrictions may have been lifted for people with HIV but people who are sex workers or drug users remained firmly persona non grata and few attended this meeting.

Three voices that were heard, however, belonged to a young gay doctor from Uganda, an advocate for sex workers and Debbie, the transgender woman who happened to be Black, an ex-drug user and sex worker. And what was common to the accounts of all three of these people was that in each of their cases, care and support for their predicaments and susceptibility to HIV came not from HIV services which were integrated within public or primary health care services-as per investment framework recommendations, but rather, from specific services focussed on the unique social practices of particular populations. That is where they found acceptance, non-discriminatory care, support, testing and, where needed, treatment. This was a salutary reminder that we cannot adopt universal responses to the needs of people affected by HIV; we need to carefully think on the policy mantra of integrating HIV treatment and care into public and primary health services, for in so many places where this occurs these people will still miss out. This was for me a rare instance of social practice being voiced at the conference.

Other conference sessions included "HIV Diagnosis and HAART Initiation: Don't Be Late" [10], which listed presentations such as "Cost-effectiveness of More Frequent HIV Screening of men who have sex with men in the United States [11].

What was this likely to mean then, for the ways Australia, and others, do development business - and the author uses that phrase deliberately - with their regional colleagues to help them address their HIV epidemics? Well, we had an insight to this in Washington as well, in a Tuesday evening session [12], AusAID and UNAIDS profiled the recently released HIV in Asia-Transforming the Agenda for 2012 \& Beyond, Report of a Joint Strategic Assessment in Ten Countries [13]. The objective of this report was to "provide advice to donors... governments and their partners for future policy, programming and partnerships for HIV in Asia... informed by... evidence of best practice and cost-effectiveness" [14]. Commendably, this report notes that unless and until HIV incidence among MSM, people who inject drugs, sex workers, transgender people and people, in "closed settings" are prioritized, impacts will be minimal.

Nevertheless, the bulk of this report was devoted to consideration of the Global Financial Crisis, strategic 

Treatment and Prevention: Human Rights and Public Health, Different...But the Same?

financial investment, levels of domestic $\mathrm{v} / \mathrm{s}$ international funding and misdirection of funding; it strongly recommends an "investment approach" to HIV responses. There is much in this report which is important and of value. While it targets key affected populations for that investment, a number of panel discussants and members of the audience felt that it did not sufficiently emphasise the necessity of their involvement in that process. It is about implementation but its implementers are "donors, government and their partners" [14]. With its focus firmly on the economic and institutional, there is a real risk that those partners are going to be less broad-based civil society and more business and financial.

Another report, also about implementation and made available at the Washington conference by a coalition of community based organisations in Australia including AFAO, NAPWA, Anwernekenhe, Scarlet Alliance and AIVL_ - presented a more considered and inclusive approach to change. This report, Implementing the United Nations Political Declaration on HIV/AIDS in Australia's Domestic HIV Response: Turning Political Will Into Action [15], also advocated change and the considered implementation of new scientific findings, but repeatedly reminded its audience that, in order to implement new science and change, there must also be "commitments to... increase funding to the HIV and AIDS response... to continue engaging people living with and affected by HIV in decision making and planning, implementing and evaluating.... and to partner with local leaders and civil society..." [15]. These partnerships, it noted, are required "to manage the complexity of academic and community knowledge in social, behavioral, medical and scientific domains that underpin an effective HIV response" [15].

There is, the author believes, an extant risk that in a time of shrinking investment in the international HIV response, funding for civil society engagement and support is and will continue to be shrinking disproportionally to funding that is seen to be specifically focussed on supporting implementation of "new scientific findings". And right now that means treatment as prevention, and addressing barriers to implementation that are defined as economic, institutional and programmatic.

\section{Conclusions}

We could approach the international HIV agenda, as presented at AIDS2012, from a number of critical viewpoints - the false distinction between interventions cast as either biomedical or behavioral; the confusion of treatment with prevention; the positioning of a moral obligation to public health as tantamount to human rights, and; the varying capacities of countries to even consider treatment as prevention within their national guidelines and programs. Time does not allow me to address these in sufficient detail here.

Briefly, the WHO Programmatic Update on ART treatment as prevention of HIV and TB [16], issued in June of 2012, looked at guidelines for ART initiation criteria across 72 countries and regions. At the time and within the Asia and Pacific regions, most countries' guidelines advocated treatment initiation at CD4 $<$ or equal to 350 , though others were still at $<$ or equal to 200. Most interesting was that while the new science rhetoric of Washington and the investment framework being referenced by donors talked of targeting key affected populations, none of the 72 countries reviewed in the WHO study had any recommendations for treatment as prevention, or ART, for sex workers and most made no mention of it for drug users or MSM. At the risk of stating the obvious and perhaps being somewhat disingenuous, the report noted:

Programme managers face difficult decisions in how to best use their limited resources for interventions that have the greatest impact on reducing HIV-related morbidity and mortality and new HIV infections, while ensuring that equity and ethical issues are considered [16].

Implementation will simply not occur without the 

Treatment and Prevention: Human Rights and Public Health, Different...But the Same?

active participation of affected communities, Adam has pointed out "that any intervention in the epidemic", whether it is understood as "biomedical", "behavioral" or both, requires community engagement and mobilization in order to stand any chance of success" [1]. Kippax and Stephenson have noted that "the contemporary distinction between biomedical, behavioral and structural forms of prevention functions to cloud our understanding of what effective prevention is and the mechanisms involved in its effectiveness" [4].

There is much to be said about the ways that human rights and public health are being positioned within the international HIV response. At one level, suffice it to say that public health and human rights are not the same thing; their subjects differ in profound ways. The authority of public health and the authority of human rights derive from different conceptions of identity, citizenship and the state. Human rights are premised on a foundation of morality or ethics; as a discourse it employs notions of universality, obligation and the common good and employs an intuitive reasoning. Public health is premised on a foundation of pragmatism. It employs scientific method and attendant notions of uniformity, social responsibility and the common good. In the domain of international HIV policy, the science of public health and the intuitivism of human rights have been combined in order to persuade human behaviors and shape states' policies. That combination however, unravels on a number of fronts. It imbues the science of public health with the morality of human rights. A consequent narrative of moral authority has emerged in policy, particularly as it pertains to prevention strategies and treatment options and the expected behaviors of policy subjects. At the same time, human rights, when they are contained within a universal human rights model and presented as justice, reflect Derrida's assertion of prioritizing "the generality of a rule, norm or universal imperative" [17] over the singular experiences of its subjects. This inevitably comes up against the discontinuities and lived realities of those subjects; again, in Derrida's terms, the "irreplaceable existences" [17] of people with and affected by HIV.

The positioning of public health and human rights within international HIV policy requires that we ask whether human rights have delivered control and justice to people with and affected by HIV, or simply served to deliver better public health outcomes, measured in solely biomedical terms of clinical markers and epidemiological data. It is doubtful that the "right to treatment", so often invoked by public health and human rights advocates, as well as representatives of HIV affected populations, represents and encapsulates the broad spectrum of rights being articulated in different settings, by different populations. It must also be considered whether this reduction of rights, which are locally understood and felt, transforms a right into a compulsion to prescribed behavior, backed up by the power of the aforementioned assumption of moral authority.

The so called "human rights framework", applied so blithely to our duty to implement treatment as prevention, is a distorting mechanism. It filters a panoply of rights narratives, of justice and dignity, into a single strand of meaning, used to shape a particular response, at both the individual and community levels, to the public health aims of policy and the state. Put differently, it effectively filters out rights as economic, social and cultural and represents them in solely civil and political terms.

Biehl notes that, "as the public health paradigm shifted from prevention to treatment access, political rights... moved toward biologically based rights" [20]. In this process "medical survival has been established as a matter of citizenship and politics" and policy is cast as lifesaving, but only inasmuch as it "fits a neoliberal paradigm which emphasises economic criteria" [18]. In this process, human rights are biomedical rights which the state is charged with protecting and thus, the market is moralized. Part of this process involves what Biehl termed the 

Treatment and Prevention: Human Rights and Public Health, Different...But the Same?

"pharmaceuticalization of public health" and its magic bullet approaches; magic bullets that now state "treatment is a matter of prevention", and "human rights is a matter of public health", and which assume the biomedical is not also a matter of the behavioral [18].

So, in conclusion, where does this leave the subject of treatment as prevention policy? There is of course a great need to extend the opportunity of treatment to all people with HIV along with the technologies and practices of prevention.

But these are all embedded in social practice. The implementation of treatment as prevention, as a universal, technology of effectiveness, mistakenly applies a universal remedy and anticipates a universal outcome. It further essentialises an ideal, universal subject; one that is vulnerable, at risk, marginalised, poor, Black, female, cast at times as irresponsible and now in need of rescuing by a moralised scientific agenda. At the same time, this approach fails to see that those subjects, by virtue of their vulnerability to and perceptions of risk, will be peripheral, resistant, contesting and difficult; at times proudly so. And in this they will, in effect, be exercising their fundamental human rights to agency, consent and choice.

Treatment as prevention, along with all other interventions, will never be the sole means to an "AIDS- free generation", while it is conceived solely as biomedical and while it sees its obstacles solely in terms of economics and investment efficiencies. As long as it does this, it risks compromising the effectiveness of both treatment and prevention when both are sorely needed by so many people.

\section{Acknowledgements}

The author acknowledges the assistance and advice of Levinia Crooks, Chief Executive Officer Australasian Society for HIV Medicine, Adjunct Associate Professor Public Health and Human Biosciences La Trobe University, Melbourne Australia; Emeritus Professor Susan Kippax, Social Policy
Research Centre University of New South Wales, Sydney Australia; Professor Heather Worth, Head International Program, International HIV Research Group, School of Public Health and Community Medicine, University of New South Wales, Sydney Australia

\section{References}

[1] Adam, B. 2011. "Epistemic Fault Lines in Biomedical and Social Approaches to HIV Prevention." Journal of the International AIDS Society 14 (2): S2.

[2] AIDS, 2012. XIX International AIDS Conference July 22-27 Washington, DC, USA. Accessed June 17, 2015. http://pag.aids2012.org/PAGHome.aspx?tab=1.

[3] AIDS, 2010. "Rights Here, Right Now." Presented at the XVIII International AIDS Conference, Vienna, Austria. Accessed June 17, 2015. http://www.aids2010.org/.

[4] Kippax, S., and Stephenson, N. 2012. "Between Biomedical and Social Dimensions of HIV." American Journal of Public Health May 102, (5): 789-99.

[5] Kippax, S., Reis, E., and De Wit, J. 2011 "Two Sides of the HIV Prevention Coin." AIDS Education and Prevention 23 (5): 393-6.

[6] Daily Bulletin News and Information from the XIX International AIDS Conference 21-22 July 2012 Edition1. Accessed June 17, 2015. http://www.aids2012.org/WebContent/File/Daily_Bulleti n/AIDS2012_Daily\%20Bulletin_Edition\%201_EN.pdf.

[7] Fauci, A. 2012. "Ending the HIV Epidemic: From Scientific Advances to Public Health Implementation." Presented at AIDS 2012 XIX International AIDS Conference, Washington DC, USA. Accessed June 17, 2015. http://pag.aids2012.org/flash.aspx?pid=1559.

[8] UNAIDS 2011. "HIV and Social Protection Guidance Note.” UNAIDS Switzerland. Accessed June 17, 2015. http://www.unicef-irc.org/files/documents/d-3827-HIV-a nd-Social-Protection.pdf.

[9] UNAIDS Issues Brief, 2011. "A New Investment Framework for the Global HIV Response." UNAIDS Switzerland. Accessed June 17, 2015. http://icssupport.org/wp-content/uploads/2012/02/3-Inves tment-Framework-Summary-UNAIDS-Issues-Brief.pdf.

[10] Oral Abstract Session, 2012. "HIV Diagnosis and HAART Initiation: Don't Be Late!” Presented at the AIDS 2012 XIX International AIDS Conference, Washington DC, USA. Accessed June 17, 2015. http://pag.aids2012.org/session.aspx?s=249.

[11] Hutchinson, A., Sansom, S., and Farnham, P. 2012. "Cost-Effectiveness of More Frequent HIV Screening of Men Who Have Sex with Men in the United States." 
Human Rights and Public Health in the International HIV Response: Issues of Contested Control, Treatment and Prevention: Human Rights and Public Health, Different...But the Same?

Presented at AIDS 2012 XIX International AIDS Conference, Washington DC, USA. Accessed June 17, 2015. http://pag.aids2012.org/session.aspx?s=249.

[12] UNAIDS and Australian Agency for International Development (AusAID) 2012. "HIV in Asia: Transforming the Agenda for 2012 and Beyond." Non-commercial satellite. Presented at the AIDS 2012 XIX International AIDS Conference, Washington DC, USA. Accessed June 17, 2015. http://pag.aids2012.org/session.aspx?s=52.

[13] Godwin, P. 2012. "Transforming the Agenda for 2012 and Beyond. Report of a Joint Strategic Assessment in Ten Countries." Presented at AIDS 2012 XIX InternationalAIDS Conference, Washington DC, USA. Accessed June 17, 2015. http://www.aids2012.org/webcontent/file/pag/Tuesday.pd f.

[14] Godwin, P., and Dickinson, C., 2012. "HIV in Asia Transforming the Agenda for 2012 and Beyond. Report of a Joint Assessment in Ten Countries. Final Report."AusAID, UNAIDS, USAID, WHO, UNFPA,
UNODC, UNDP, World Bank, ADB and the Global Fund. Accessed June 17, 2015. http://dfat.gov.au/about-us/publications/Documents/hiv-st rategic-assessment-report.pdf.

[15] Australian Federation of AIDS Organisations 2012. "Implementing the United Nations Political Declaration on HIV/AIDS in Australia's Domestic HIV Response: Turing Political Will into Action.” AFAO, Anwernekenhe, Scarlet Alliance and AIVL et al. Accessed June 17, 2015. http://www.afao.org.au/library/topic/treatment/DP0912_I mplementing-the-UNPD-in-Australia.pdf.pdf.

[16] WHO 2012. "Programmatic Update Antiretroviral Treatment as Prevention (TASP) of HIV and TB." World Health Organization. Switzerland. Accessed June 17, 2015.

http://whqlibdoc.who.int/hq/2012/WHO_HIV_2012.12_e ng.pdf?ua $=1$.

[17] Derrida, J. 2002. Acts of Religion. New York: Routledge Press.

[18] Biehl, J. 2007. Will to Live, AIDS Therapies and the Politics of Survival. Princeton: Princeton University Press. 